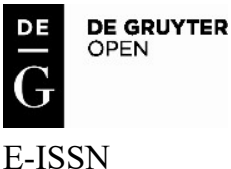

2450-8594

\title{
DYNAMIC REDUCTIONS FOR THE NONLINEAR SOIL-FOUNDATION-STRUCTURE SYSTEM INTERACTIONS
}

\author{
Volodymyr O. Sakharov \\ University of Zielona Gora, Zielona Góra, Poland
}

\begin{abstract}
The article presents new dynamic superelements for DOF (degrees of freedom) reduction. Proposed spectral superelements (SES) are based on the method of normal coordinates. The developed superelements with basis nodes (SEB) for the inhomogeneous systems are also shown. Proposed superelements ensure to obtain the diagonal matrix of masses which allow to use the efficiency of explicit method. The results of nonlinear analysis using proposed reduction method for the group of high-rise building are presented. The calculations were performed by explicit method with the help of Automated System of Scientific Research (ASSR) "VESNA-DYN".
\end{abstract}

Keywords: finite element method, spectral superelement, diagonal matrix, SES, SEB, explicit method, VESNA-DYN, high-rise building, nonlinear analysis

\section{INTRODUCTION}

The design of the high-rise building at seismic hazardous area requires the detailed analysis of the stress-strain state constriction in the soil base.

There are many methods available for the assessment of the effect of seismic loads on the stress-strain state of structures, such as methods of the static theory, spectral methods, and the group of direct dynamical methods. But only direct dynamical methods can give the most complete information about the behaviour of a construction. Some of the methods such as the Method of Normal Coordinates are guaranteed only in the case where the viscosity of a material that causes the damping of oscillations, is taken as an average. Most building structures are characterized by the presence of the multiple structural elements. The finite- 
element models of substructures (known as superelements) are developed independently with the formulation of contact conditions for the joint operation in the composition of the construction under study. This allows one to apply the methods most efficient for the corresponding superelements and to significantly improve overall efficiency of the calculations due to the such combined approach. In order to account for the structural peculiarities of buildings, methods based on the decomposition of the system can be used - ensuring separation of substructures that are have homogeneous or similar properties. By the conclusions of many experts, at most a half of the eigenmodes in the lower part of the spectrum of FEM has the crucial meaning (this was taken into account in the norms of the USA concerning the construction in the nuclear power industry [5]). Also, in the book [4] the attention is paid to the circumstance that dynamical properties of FEM have a higher level of approximation than mechanical ones.

\section{DYNAMIC SPECTRAL REDUCTION}

Most building structures are characterized by the presence of multiple structural elements, so it is convenient to use the method of superelements. In this work the finite-element models of substructions called the superelements are developed independently with the formulation of contact conditions for the joint operation in the composition of the construction.

The different techniques of DOF reduction including superelement technology are presented in [4]. Also it is noticed that the superelement for the dynamic problems formulated by the Craig-Bampton scheme has higher accuracy than the static superelement due to the introduction of modal coordinates.

The practice has shown that the superelements constructed on the eigenmodes of oscillations of the sub-constructions with a diagonal matrix of masses are the most efficient for the explicit methods (spectral superelements (SES) [1,3]).

\subsection{Superelements based on method of normal coordinates (SES)}

There should be a 12-point space before and a 2-point space after each subsection. As one of the most efficient methods of dynamical reduction, is the method of normal coordinates with expansion the displacements in the eigenmodes. In this case we need to calculate only the lower part of the spectrum of eigenmodes.

One of them is the superelement which based on the Craig-Bampton method. For the defined substructure it is necessary to distinguish the internal and external parts. The nodes, by which the substructure contacts with other parts of construction, are called external (Fig. 1), and the elements, which include at least one external node are called external elements. The nodes and elements, which remain in the substructure, are referred to as internal ones. 


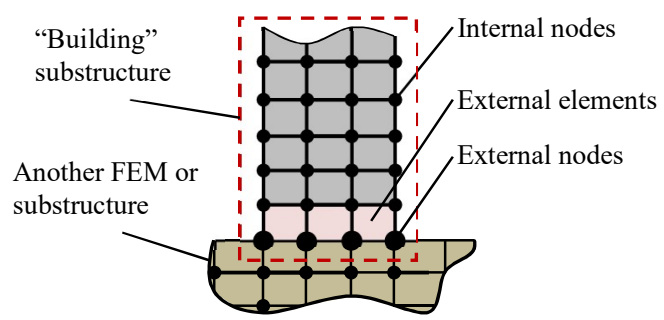

Fig. 1. Definition of external and internal parts of a superelement for the substructure

According to the work [3], the matrix of reduction [S] is formed by the method of normal coordinates from the eigenmodes of a substructure for the internal nodes and by the method of static condensation for the external nodes. For this purpose, the eigenmodes of a substructure are determined and normalized in the first turn at fixed external nodes $\left[\mathrm{R}_{\mathrm{ii}}\right]$. Then the matrix [S] is supplemented by the displacements caused by the unit displacements of the external nodes $\left[\mathrm{X}_{\mathrm{ei}}\right]$ :

$$
[\mathrm{S}]=\left[\begin{array}{cc}
{\left[R_{i m}\right]} & {\left[X_{i e}\right]} \\
0 & {\left[E_{e e}\right]}
\end{array}\right]
$$

where: $\left[R_{i m}\right]-$ is the collection of vector-columns of the normalized eigenmodes of a substructure for internal nodes; $\left[X_{i e}\right]$ - the collection of e vectors-columns of the displacements of internal nodes under single displacements of external nodes; and $\left[\mathrm{E}_{\mathrm{ee}}\right]-$ is the identity matrix, whose order is equal to the number of external displacements.

The reduced matrix of masses $[\widetilde{\mathrm{M}}]$ can be calculated by (2):

$$
\begin{gathered}
{[\widetilde{\mathrm{M}}]=[\mathrm{S}]^{T}[\mathrm{M}][\mathrm{S}]=} \\
=\left[\begin{array}{cc}
{\left[R_{m i}\right]^{T}} & {\left[X_{e i}\right]^{T}} \\
{[0]} & {\left[E_{e e}\right]}
\end{array}\right]\left[\begin{array}{cc}
{\left[M_{i i}\right]} & {[0]} \\
{[0]} & {\left[M_{e e}\right]}
\end{array}\right]\left[\begin{array}{cc}
{\left[R_{i m}\right]} & 0 \\
{\left[X_{e i}\right]} & {\left[E_{e e}\right]}
\end{array}\right]
\end{gathered}
$$

The obtained matrix will be "framed" and will poses a non-diagonal matrix, which does not allow one to efficiently apply the explicit integration schemes.

\subsection{Superelements of spectral type with diagonal matrix of mas}

The headers of even pages should include the authors' surnames, the headers of odd pages should include (in the place of "Instructions to authors") an expression related to the text of the paper (e.g. the whole title of the paper or its part).

In the proposed version the superelement have a diagonal structure of matrix of mass and also applied the independent formulation of contact conditions on external part of substructure, which allow increasing the reduction rate. The matrix of reduction $[S]$ has the form (3): 


$$
[S]=\left[\begin{array}{cc}
{\left[R_{i n}\right]} & 0 \\
0 & {\left[E_{e e}\right.}
\end{array}\right]
$$

where $\left[R_{i n}\right]$ - is the collection of $\mathrm{n}$ vector-columns of the normalized eigenmodes of the substructure for internal nodes obtained with possibility of change the stiffness of external elements; $\left[E_{e e}\right]-$ is the identity matrix.

The submatrix [R] obtained from the eigenmodes of substructure of internal nodes with additional modification of stiffness matrices for external elements by $\mathrm{kz}$ factor (Fig. 2). In a case where the stiffness of external elements is nonzero, the matrix $\left[R_{i m}\right]$ in (1) is supplemented by missed vectors-columns of hard displacements of internal nodes. All these vectors are orthonormalized with themselves and matrix of mass. In this case the matrix of masses will have a diagonal form (4):

$$
\begin{gathered}
{[\widetilde{\mathrm{M}}]=[\mathrm{S}]^{T}[\mathrm{M}][\mathrm{S}]=} \\
=[M]_{S E S}=\left[\begin{array}{cc}
{\left[R_{\text {in }}\right]^{T}\left[M_{i i}\right]\left[R_{\text {in }}\right]} & {[0]} \\
{[0]} & {\left[M_{e e}\right]}
\end{array}\right]=\left[\begin{array}{cc}
{[I]} & {[0]} \\
{[0]} & {\left[M_{e e}\right]}
\end{array}\right]
\end{gathered}
$$

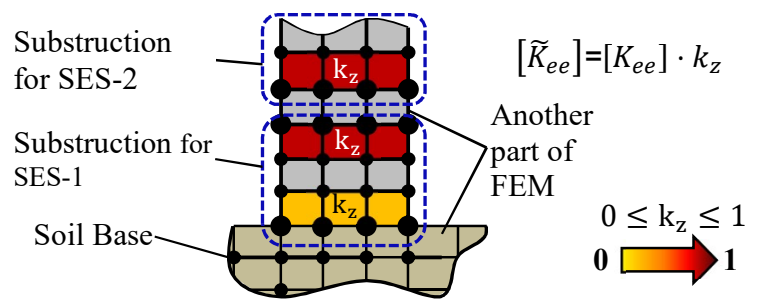

Fig. 2. Substructures topology of the high-rise building for the SES-superelements

To take into account the peculiarities of the substructure interaction with other parts of the FEM, $\mathrm{k}_{\mathrm{z}}$ factor of matrices of stiffness of external elements is used with $0 \leq \mathrm{k}_{\mathrm{z}} \leq 1$.

\subsection{SES superelements formation algorithm}

The process of formation of a spectral superelement is reduced to the following sequence of actions:

1. Define the external and internal displacements and external and internal elements of substructure.

2. Enumerate the nodal displacements by order: firstly, all $n_{i}$ internal displacements and then $\mathrm{n}_{\mathrm{e}}$ external ones.

3. Form the matrix of masses of FEM of the substructure: 


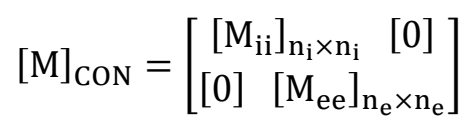

where $\left[\mathrm{M}_{\mathrm{ii}}\right]$ - is any positive definite symmetric matrix, $\left[\mathrm{M}_{\mathrm{ee}}\right]$ - is the diagonal matrix of external nodes.

4. Multiply the matrices of stiffness of external elements $\left[\widetilde{K}_{e e}\right]$ by the coefficient $\mathrm{k}_{\mathrm{z}}$, and to form the modified matrix of stiffness of FEM of the substructure:

$$
[\widetilde{\mathrm{K}}]_{\mathrm{CON}}=\left[\begin{array}{cc}
{\left[\widetilde{\mathrm{K}}_{\mathrm{ii}}\right]} & {\left[\widetilde{\mathrm{K}}_{\mathrm{ie}}\right]} \\
{\left[\widetilde{\mathrm{K}}_{\mathrm{ei}}\right]} & {\left[\widetilde{\mathrm{K}}_{\mathrm{ee}}\right]}
\end{array}\right]
$$

where $\left[\widetilde{\mathrm{K}}_{\mathrm{ee}}\right]=\left[\mathrm{K}_{\mathrm{ee}}\right] \cdot \mathrm{k}_{\mathrm{z}}$, where $0 \leq \mathrm{k}_{\mathrm{z}} \leq 1$.

The $\mathrm{k}_{\mathrm{z}}$ factor is chosen based on the peculiarities of the interaction of the substructure with other parts of FEM. For example, if we form a spectral superelement of a sufficiently stiff building, which contacts with a pliable soil base, then it is expedient to set $\mathrm{k}_{\mathrm{z}}$ to be zero, because the base affects slightly the main modes of oscillations of a building. For a rock base, $\mathrm{k}_{\mathrm{z}}$ can be set to be 1 . But it is worth to emphasize that the choice of $\mathrm{k}_{\mathrm{z}}$ has no influence on the convergence of the solutions of problems. Irrespective of the value of $\mathrm{k}_{\mathrm{z}}$, the precision of the representation of FEM properties of the substructure by a superelement increases with the number of involved modes of oscillations. If the number of modes is equal to the number of internal degrees of freedom (i.e., without a reduction), then the superelement exactly corresponds to the substructure. The successful choice of $\mathrm{k}_{\mathrm{z}}$ factor, can only decrease the number of involved modes needed for the necessary accuracy of results.

5. Impose the boundary on external nodes, and set all external displacements to zero. Solve the partial problem of determination of the necessary eigenfrequencies and eigenmodes of oscillations in the lower part of the spectrum of the substructure

$$
\left(\left[\widetilde{\mathrm{K}}_{\mathrm{ii}}\right]-\omega^{2}\left[\mathrm{M}_{\mathrm{ii}}\right]\right)\left\{\mathrm{u}_{\mathrm{i}}\right\}=0
$$

6. Calculate the reduction matrix [S]. In case of $\mathrm{k}_{\mathrm{z}}>0$, add six modes of rigid displacements of the internal nodes and orthogonalize them with another modes determined earlier. In the case of a linear dependence, the corresponding mode is omitted. The obtained modes determine the basis (eigenmodes) and the matrix of reduction for the internal degrees of freedom $\left[\mathrm{S}_{\mathrm{i}}\right]$.

7. Form the real matrix of stiffness $[\mathrm{K}]_{\mathrm{CON}}$ of FEM of the substructure with the non modified stiffness for the external elements. E.g. by the matrices of stiffness of external elements multiplied by the coefficient $\left(1-\mathrm{k}_{\mathrm{z}}\right)$ : 


$$
[\mathrm{K}]_{\mathrm{CON}}=\left[\begin{array}{ll}
{\left[\mathrm{K}_{\mathrm{ii}}\right]} & {\left[\mathrm{K}_{\mathrm{ie}}\right]} \\
{\left[\mathrm{K}_{\mathrm{ei}}\right]} & {\left[\mathrm{K}_{\mathrm{ee}}\right]}
\end{array}\right]
$$

8. Calculate the reducted matrix of stiffness and matrix of masses of the superelement:

$$
\begin{gathered}
{[\mathrm{K}]_{\mathrm{SES}}=\left[\begin{array}{cc}
{\left[\mathrm{S}_{\mathrm{i}}\right]^{\mathrm{T}}\left[\mathrm{K}_{\mathrm{ii}}\right]\left[\mathrm{S}_{\mathrm{i}}\right]} & {\left[\mathrm{S}_{\mathrm{i}}\right]^{\mathrm{T}}\left[\mathrm{K}_{\mathrm{ie}}\right]} \\
{\left[\mathrm{K}_{\mathrm{ei}}\right]\left[\mathrm{S}_{\mathrm{i}}\right]} & {\left[\mathrm{K}_{\mathrm{ee}}\right]}
\end{array}\right]} \\
{[\mathrm{M}]_{\mathrm{SES}}=\left[\begin{array}{cc}
{\left[\mathrm{S}_{\mathrm{i}}\right]^{\mathrm{T}}\left[\mathrm{M}_{\mathrm{ii}}\right]\left[\mathrm{S}_{\mathrm{i}}\right]} & {[0]} \\
{[0]} & {\left[\mathrm{M}_{\mathrm{ee}}\right]}
\end{array}\right]=\left[\begin{array}{cc}
{[\mathrm{I}]} & {[0]} \\
{[0]} & {\left[\mathrm{M}_{\mathrm{ee}}\right]}
\end{array}\right]}
\end{gathered}
$$

where [I] is the identity matrix.

The matrix of stiffness of a spectral superelement is slightly filled and is stored in a special format convenient for the application of efficient algorithms executing some actions over the matrices. The matrix of masses is conserved in the form of a vector-diagonal. The matrix of reduction $\left[S_{i}\right]$ is also preserved for the calculation of the displacements of internal nodes of the substructure in terms of generalized displacements of the superelement.

\section{DYNAMICAL SUPERELEMENTS FOR INHOMOGENEOUS SYSTEMS AND COMBINED SUPERELEMENTS}

The superelements constructed on the basis of the expansion in the eigenmodes of oscillations were successfully used in dynamical calculations of a lot of constructions in the cases where the eigenmodes corresponding to the lower part of the spectrum of eigenfrequencies were applied. Such approach is based on the reasoning that the errors of the approximation of modes increase with the frequency of oscillations, which is true for the homogeneous constructions. If the dynamical behaviour of inhomogeneous systems including the "soil base foundation - building" system is analysed, such conclusion does not correspond to the reality.

The accuracy of approximation of the eigenmodes can be related to the number of elements, which can represent a wave with length $\mathrm{L}_{\omega}$ corresponding to the frequency $\omega$ of the environment. If polylinear finite elements are used, their number $\mathrm{n}_{\omega}$ for the representation of a wave with length $\mathrm{L}_{\omega}$ at the frequency $\omega$ should be $n_{\omega} \geq 6$ (three for a half-wave), since a less number $\left(6>n_{\omega} \geq 3\right.$ ) will lead to large errors or the wave cannot be described for $3>n_{\omega}$. The wavelength is proportional to the period of oscillations $\mathrm{T}_{\omega}$ and to the velocity of propagation $c_{\omega}$. The value of $L_{\omega}$ for a longitudinal wave is as follows: 


$$
L_{\omega}=T_{\omega} c_{\omega}=\frac{2 \pi}{\omega} c_{\omega}=\frac{2 \pi}{\omega} \sqrt{\frac{E(1-v)}{m(1-2 v)}},
$$

where $E, v, m$ are the modulus of elasticity, Poisson's ratio, and the density of the environment. Let us denote the characteristic size of finite elements by $h$. For $L_{\omega}=h n_{\omega}$, we obtain the condition of limitation for the use of the eigenmodes due to the limitation of the corresponding eigenfrequencies:

$$
\omega=\frac{2 \pi}{L_{\omega}} c_{\omega}=\frac{2 \pi}{h n_{\omega}} c_{\omega} \leq \frac{1}{h} \sqrt{\frac{E(1-v)}{m(1-2 v)}} .
$$

From whence, it is seen that, for the materials possessing essentially different physico-mechanical properties, criteria (12) for the choice of eigenmodes will be also significantly different. In other words, the method of reduction based on the traditional expansion in eigenmodes, which are selected by the single criterion (values of eigenfrequencies) is not suitable for the description of such inhomogeneous media as the soil base, etc. In this case, it is more expedient to use the method of basis nodes with the Guyan dynamical reduction or with the concentration of the total mass in basis nodes. The precondition is the requirement for the external elements to possess the diagonal matrices of masses. In order to construct the spectral superelements on basis nodes with a diagonal matrix of masses, we will apply the method of spectral elements without a reduction of internal dynamical degrees of freedom.

\subsection{Superelements based on Guyan's basis nodes (SEB) for inhomogeneous systems}

The order of the formation of a SEB superelement is realized according to the stages given in 2.3:

1. To determine external and internal displacements and external and internal elements of the substructure. To separate the basic displacements among the internal ones.

2. To enumerate all displacements by order: firstly the internal nonbasic $n_{i}$ displacements and then basic $n_{b}$ and external $n_{e}$ ones.

3. To form the matrix of masses of FEM of the substructure:

$$
[M]_{C O N}=\left[\begin{array}{ccc}
{\left[M_{i i}\right]} & {\left[M_{i b}\right]} & {[0]} \\
{\left[M_{b i}\right]} & {\left[M_{b b}\right]} & {[0]} \\
{[0]} & {[0]} & {\left[M_{e e}\right]}
\end{array}\right],
$$


where $\left[M_{i i}\right]$ is a positive definite symmetric matrix;

$\left[M_{e e}\right]$ is the diagonal matrix of external nodes,

4. To multiply the matrices of stiffness of external elements by the coefficient $\mathrm{k}_{\mathrm{z}}$ possessing values in the interval $0 \leq k_{z} \leq 1$ and to form the corrected matrix of stiffness of FEM of the substructure:

$$
[\widetilde{K}]_{C O N}=\left[\begin{array}{lll}
{\left[\widetilde{K}_{i i}\right]} & {\left[\widetilde{K}_{i b}\right]} & {\left[\widetilde{K}_{i e}\right]} \\
{\left[\widetilde{K}_{b i}\right]} & {\left[\widetilde{K}_{b b}\right]} & {\left[\widetilde{K}_{b e}\right]} \\
{\left[\widetilde{K}_{e i}\right]} & {\left[\widetilde{K}_{e b}\right]} & {\left[\widetilde{K}_{e e}\right]}
\end{array}\right],
$$

5. To construct the subsystem of equations

$$
\left(\left[\begin{array}{cc}
{\left[\widetilde{K}_{i i}\right]} & {\left[\widetilde{K}_{i b}\right]} \\
{\left[\widetilde{K}_{b i}\right]} & {\left[\widetilde{K}_{b b}\right]}
\end{array}\right]+\left[\begin{array}{ll}
{\left[M_{i i}\right]} & {\left[M_{i b}\right]} \\
{\left[M_{b i}\right]} & {\left[M_{b b}\right]}
\end{array}\right]\right)\left\{\begin{array}{l}
\{u\}_{i} \\
\{u\}_{b}
\end{array}\right\}=0,
$$

6. As at the static condensation (without regard for inertial forces), to determine the displacements $\{u\}_{i}$ in terms of $\{u\}_{b}$ :

$$
\{u\}_{i}=-\left[\widetilde{K}_{i i}\right]^{-1}\left[\widetilde{K}_{i b}\right]\{u\}_{b}=[T]\{u\}_{b},
$$

7. To restore the matrix of stiffness of the substructure and to substitute these displacements in the dynamical equations (15), where the real matrices (13) are used instead of matrices (14). To multiply the first equation by the matrix $[T]^{T}$ and to add the equations, which gives the reduced system:

$$
\left(\left[\overline{\bar{K}}_{b b}\right]+\left[\overline{\bar{M}}_{b b}\right]\right)\{u\}_{b}=0,
$$

where:

$$
\begin{gathered}
{\left[\overline{\bar{K}}_{b b}\right]=[T]^{T}\left[K_{i i}\right][T]+[T]^{T}\left[K_{i b}\right]+\left[K_{b i}\right][T]+\left[K_{b b}\right],} \\
{\left[\overline{\bar{M}}_{b b}\right]=[T]^{T}\left[M_{i i}\right][T]+[T]^{T}\left[M_{i b}\right]+\left[M_{b i}\right][T]+\left[M_{b b}\right],}
\end{gathered}
$$

8. To orthogonalize $\{u\}_{b}$ with the matrix $\left[\bar{M}_{b b}\right]$ by the Gram-Schmidt process and to determine the matrix of transformation $[A]$, which satisfies the condition of orthogonality:

$$
\{u\}_{b}=[A]\{\overline{\bar{u}}\}_{b}, \quad\{\overline{\bar{u}}\}_{b}^{T}\left[\overline{\bar{M}}_{b b}\right]\{\overline{\bar{u}}\}_{b}=[I],
$$

9. To form the matrices of stiffness and masses of the superelement by the relations 


$$
\begin{aligned}
& {[K]_{S E B}=\left[\begin{array}{cc}
{[A]^{T}\left[\overline{\bar{K}}_{b b}\right][A]} & {[S]^{T}\left[K_{i e}\right]+[A]^{T}\left[K_{b e}\right]} \\
{\left[K_{e i}\right][S]+\left[K_{e b}\right][A]} & {\left[K_{e e}\right]}
\end{array}\right],} \\
& {[M]_{S E B}=\left[\begin{array}{cc}
{[I]} & {[0]} \\
{[0]} & {\left[M_{e e}\right]}
\end{array}\right], \quad[S]=[T][A]}
\end{aligned}
$$

In this case, the vector of displacements of the superelement $\{u\}_{S E B}$ is composed from the generalized displacements of basis nodes $\{\overline{\bar{u}}\}_{b}$ and the displacements of external nodes $\{u\}_{e}$. The vector of internal nonbasis nodes is represented in terms of the vector $\{\overline{\bar{u}}\}_{b}$ :

$$
\{u\}_{S E B}=\left\{\begin{array}{l}
\{\overline{\bar{u}}\}_{b} \\
\{u\}_{e}
\end{array}\right\}, \quad\{u\}_{i}=[S]\{\overline{\bar{u}}\}_{b}
$$

In calculations, we conserve the matrix of stiffness, diagonal matrix of masses, rectangular matrix of reduction $[S]$, and square matrix of orthogonalization $[A]$. In a number of cases where the order of a matrix is not too large, we can use an improved version of the method of basis nodes. Its essence consists in that the orthogonalization of the vectors $\{u\}_{b}$ occurs by means of the solution of the homogeneous equation (19) and by the determination of the complete spectrum of eigenfrequencies and eigenmodes. Then the matrix $[A]$ is composed of the vectors of eigenmodes, the matrix of masses remains invariable, and the matrix of stiffness becomes slightly filled (framed). Such superelement can be considered to be combined, and its application increases the efficiency of usage of the method of basis nodes. It is worth noting that the concentration of masses only in basis nodes significantly simplifies the procedure of construction of the relations for a superelement.

\section{CALCULATION METHOD AND MATERIAL MODELS}

The calculations were executed in a nonlinear conditions by the direct integration over the time by using the explicit method of central differences with discrete steps in the spatial coordinates. Algorithm was implemented [1, 8] using Automated System of Scientific Research "VESNA-DYN".

For the soil used the developed visco-elasto-plastic model under dynamic loads was applied. The limit state is described with the developed combined model, taking into account the criteria of Mohr-Coulomb, Mises-Schleicher-Botkin, Mises and the tension condition [1]. For the concrete material the combined model which takes into account visco-elasto plasticity with dynamical hardening was used [1]. 


\section{NONLINEAR INTERACTION SIMULATION OF HIGH-RISE BUILDINGS}

The developed superelements were used for simulation of a group of high-rise buildings (12, 18 and 24-storey) in a seismically hazardous area (fig.3). The developed FEM includes a system of 1'505'383 algebraic equations. Using SES dynamic superelements composed for overhead part of buildings led to the reduction the number of degrees of freedom (DOF) by $32 \%$. The number of involved eigenmodes was 390 , bounded by eigenfrequencies up to $30 \mathrm{~Hz}$ of substructure eigenfrequency and allows performing an efficient dynamic analysis.

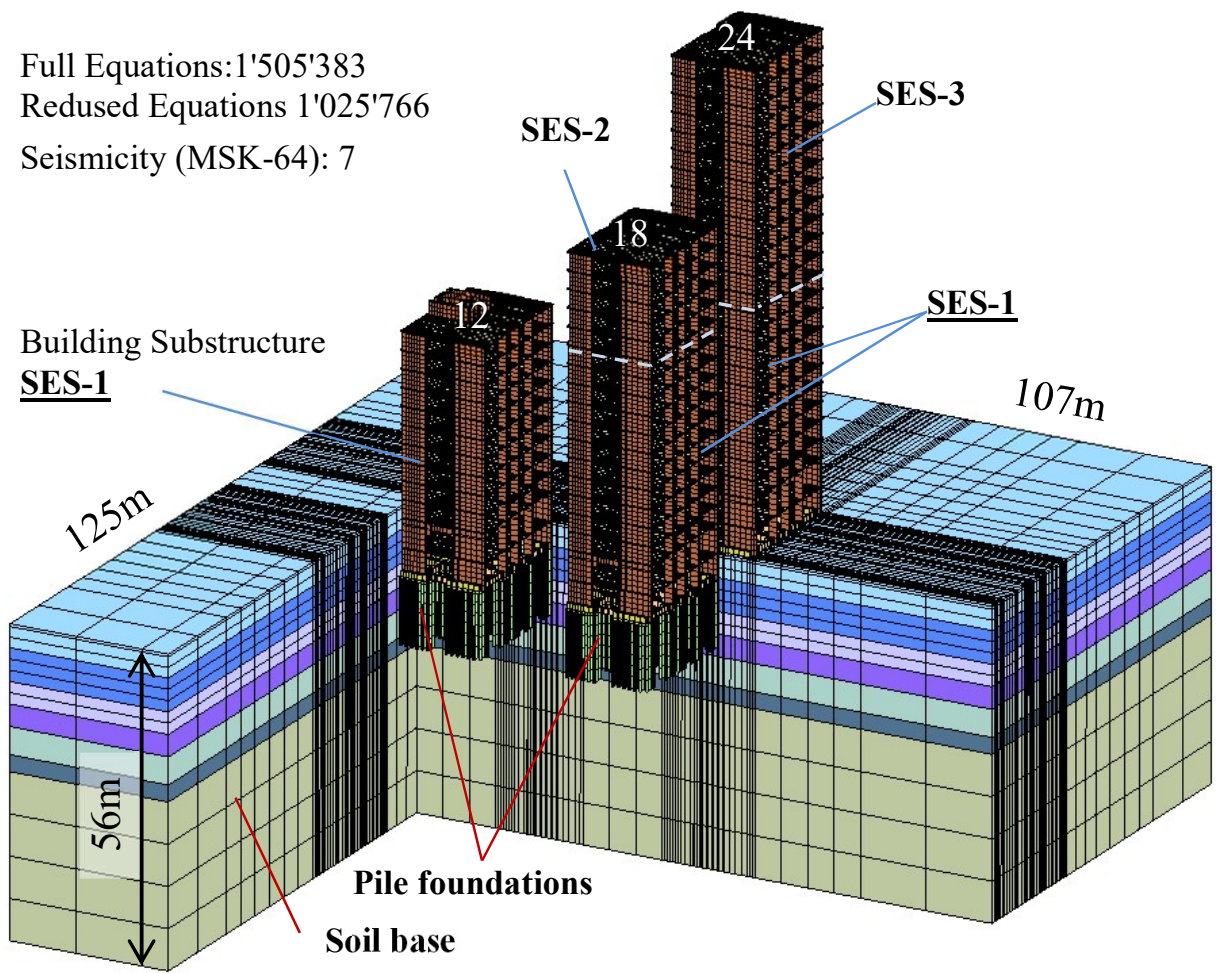

Fig. 3. Substructures topology of the high-rise building for the SES-superelements

According to the preliminary results obtained for the single 24-story building such criteria allow to reduce the number of DOF up to 2.8 times. The maximum error was less than $12 \%$ and appears at the short-term peaks of fluctuations.

The result presented in [3] show that the behavior and deformations of the three building complex significantly differ for each building. Lowest 12-story building had maximum amplitudes, that lead to the significant nonlinear deformation of the 
soil base (with piles). This is typical for the resonance mode. Predicted residual settlements for the foundation of 12, 18 and 24-storey buildings were about $5 \mathrm{~cm}$, $3 \mathrm{~cm}$ and $1 \mathrm{~cm}$ respectively. The consideration of only viscoelastic deformations causes a change in the process of deformation, especially for the foundation construction. Plastic deformations decrease the actual stiffness of piles, which affects essentially the character of a deformation of foundations.

Thus, the executed studies allow us to recommend the use of spectral superelements in the modeling of the dynamic behavior of buildings with the soil base, as well as accounting for a nonlinear deformation of the soil.

\section{CONCLUSIONS}

Based on the results of our research, we have reached the following conclusions: The new superelements for reduction of degrees of freedom were developed. They involve the peculiarities of boundary conditions for the separated substructures, which ensures the account for properties of their dynamical behavior in the composition of buildings, structures and inhomogeneous media.

The developed spectral superelements (SES) based on the method of normal coordinates provides the diagonal form matrix of masses and allows one to significantly decrease the dynamical order of the system of equations.

The approach of stiffness adjustment of SES external elements by $\mathrm{k}_{\mathrm{z}}$ factor (used for the eigenmodes only) allow to further decrease the number of involved modes needed to achieve required accuracy of results.

The method can be recommended for the different dynamical calculations of constructions in cases where the eigenmodes corresponding to the lower part of the spectrum of eigenfrequencies can be applied. This approach is based on the reasoning that the errors of the approximation of modes increase with the frequency of oscillations, which is true for the homogeneous constructions.

The developed superelement with basis nodes (SEB) based on Guayan's reduction principles provides the diagonal form matrix of masses and allows to perform reduction which is suitable for the inhomogeneous systems of construction, such as for the soil-foundation-structure interaction.

Using of proposed superelements, especially for the high-rise buildings allows one to perform the efficient dynamic analysis (with significant DOF reduction) of the soil - foundation - structure interaction, including the seismic one, with explicit integration schemes.

\section{REFERENCES}

1. Boyko, I., Sakharov, O., Sakharov, V.: Behavior of the multistory building under seismic loads with the account of the viscoplasticity of the soil base, 
Proceedings International Conference on Soil Mechanics and Geotechnical Engineering, Paris, P.1443-1446 (2013).

2. Clough Ray W., Dinamika soorurzenii (rus) [Dynamics of structures]: Transl. from english by Clough Ray W, Penzien G, M.: Stroiizdat, 1979. - 320p.

3. Craig, Jr. R.R., Bampton V.C.C. Coupling of substructures for dynamic analyses, AIAA Journal. Vol. 6, no. 7. P. 1313-1319. DOI: 10.2514/3.4741], 1968.

4. Gajan R. Privedenie matric zhjostkosti i massy. (rus.)/ Raketnaja tehnika i kosmonavtika (russk. Perevo dzhurnala American Institute of Aeronautics and Astronautics). 1965. T. 3, № 2. S. 287. [Guyan R.J. Distributed mass matrix for plate element bending // AIAA Journal. 1965. Vol. 3, no. 3. P. 567-568.].

5. NUREG - 0800. Standard Review Plan for the of Safety Analysis Report for Nuclear Power Plants [electronic document]. http://www.nrc.gov

6. Poponin V.S., Kosheutov A.V., Grigor'ev V.P., Mel'nikova V.N. (2010), Metod spektral'nykh elementov dlya resheniya ploskikh zadach dinamiki vyazkoj zhidkosti na neraznesennykh nestrukturirovannykh setkakh [The method of spectral elements for solution of plane viscous fluid dynamics problems in the unstructured unstructured grids]. The News Magazine of the Tomsk Polytechnic University. - Tomsk, Issue 2., Volume 317, P31-36.

7. Sakharov, V. (2017) Dynamic model reduction in the nonlinear interaction simulation of the neighboring high-rise buildings on the soil base, CMM2017 - 22th IC on Computer Methods in Mechanics, 13-16 September 2017, Lublin, Poland: short papers.

8. Sakharov, V.: Zastosuvannia spektralnykh superelementiv $v$ zadachakh dynamiky systemy "osnova - fundament - budivlia" [Use of spectral superelements in dynamic analysis of "soil base - foundation - building" systems]/V.O. Sakharov, Visnyk Prydniprovskoi derzhavnoi akademii budivnytstva ta arkhitektury [Bulletin of Pridniprovsk State Academy of Civil Engineering and Architecture]. - D.: PDABA, 2015.- №1(202). - P.37-46

9. Zu-Qing Qu.: Model Order Reduction Techniques with Applications in Finite Element, Springer-Verlag London, 2004. 


\title{
DYNAMICZNE REDUKCJE DLA NIELINIOWEGO MODELOWANIA INTERAKCJE SYSTEMU GRUNT-FUNDAMENT-KONSTRUKCJA
}

\begin{abstract}
Streszczenie
W artykule przedstawiono nowe dynamiczne superelementy dla redukcji DOF (stopni swobody). Proponowane superelementy spektralne (SES) są oparte na metodzie współrzędnych normalnych (wykozystanie niecałego spektrum ciestotliwosci własnej). Zostały przedstawione opracowane superelementy z węzłami podstawowymi (SEB) dla niejednorodnych układów. Proponowane superelementy zapewniają uzyskanie przekątnej macierzy mas, które pozwalają wykorzystać efektywnie metod jawnych. Zostały pokazane wyniki analizy nieliniowej z wykorzystaniem proponowanej metody redukcji dla grupy budynków wielopiętrowych. Obliczenia zostały przeprowadzone metodą jawną za pomocą Automatyzowanego Systemu Badań Naukowych (ASSR) "VESNA-DYN".

Słowa kluczowe metoda elementów skończonych, superelementy spektralne, macierz diagonalna, SES, SEB, metoda jawna, VESNA-DYN, budynek wysokościowy, analiza nieliniowa.
\end{abstract}

Editor received the manuscript: 05.03.2018 